ONLINE MUTATION REPORT

\title{
Mutation screening of the BARD1 gene: evidence for involvement of the Cys557Ser allele in hereditary susceptibility to breast cancer
}

\author{
S-M Karppinen, K Heikkinen, K Rapakko, R Winqvist
}

J Med Genet 2004;41:e1 14 (http://www.jmedgenet.com/cgi/content/full/41/9/e1 14). doi: 10.1136/jmg.2004.020669

A pproximately $5-10 \%$ of all breast and ovarian cancers are thought to arise from a hereditary predisposition to the disease, ${ }^{1}$ BRCA1 and BRCA2 being the most important susceptibility genes. ${ }^{2}{ }^{3}$ Genomic alterations in $B R C A 1$ are found in $40-50 \%$ of families with a high incidence of breast cancer ( six or more cases), and in a majority (75$80 \%$ ) of the families that display both breast and ovarian cancers. ${ }^{45}$ However, a significant portion of genetic aberrations predisposing to these cancers, especially in relatively small risk families, still remains unexplained. ${ }^{67}$ BRCAl interacts with a variety of proteins and is involved in multiple cellular processes including DNA repair, transcription, and checkpoint control. ${ }^{8-10}$ In attempts to identify new breast and ovarian cancer susceptibility genes, much research has focused on BRCAl associated proteins.

BARDI was originally identified through its interaction with BRCAl, with which it has a closely related domain structure. ${ }^{11}$ Both proteins possess an N-terminal RING finger motif and two BRCAl C-terminal (BRCT) domains present in numerous proteins involved in DNA repair and cell cycle regulation. $^{11}$ The functionally important BARDl/BRCAl heterodimer formation is mediated by the RING finger motifs and has also been shown to markedly increase the stability of both proteins. ${ }^{11-13}$ The finding of breast cancer associated mutations within the RING finger domain of $B R C A 1$, disrupting BRCAl/BARDl interaction, ${ }^{11}{ }^{14}$ and the occurrence of BARDl missense mutations in breast cancer patients, ${ }^{15-17}$ implies participation of BARDl in BRCAl mediated tumour suppression. BARDl, unlike BRCAl, also contains a centrally located sequence of three ankyrin repeats $^{11}$ that are found in many proteins involved in transcriptional regulation. ${ }^{18}$

Colocalisation of BARDl with BRCAl and RAD5l in response to DNA damage indicates a role in DNA repair, ${ }^{19}{ }^{20}$ which is supported by the recent observation of BARDl participation along with BRCAl in homology directed repair of chromosome breaks. ${ }^{21}$ Furthermore, interaction between the BARDI/BRCAl heterodimer and cleavage stimulation factor subunit 1 (CSTF1, also called CstF-50) represses the polyadenylation machinery, presumably to prevent inappropriate mRNA processing at sites of DNA repair. ${ }^{22}{ }^{23}$ The significance of BARDI/BRCAl collaboration has also been emphasised by studies of its ubiquitin ligase activity that might contribute to tumour suppression and other biological functions of BRCAl. ${ }^{24}$ In vivo substrates for the ubiquitination are not yet known, but involvement of the RNA polymerase-2 holoenzyme has been proposed. ${ }^{25}$ BARDI also regulates the subcellular localisation of BRCAl, both by translocating BRCAl into the nucleus and by inhibiting its nuclear export. ${ }^{26}$ The suggested role in TP53 dependent apoptotic signalling ${ }^{27}$ and interaction with the ankyrin repeats of proto-oncoprotein BCL3, thereby possibly modulating the activity of transcription factor NFKB, ${ }^{28}$ represent

\section{Key points}

- BARD1 interacts with BRCA1, with which it relates both structurally and functionally. Both proteins possess an $\mathrm{N}$-terminal RING finger domain and two $\mathrm{C}$-terminal BRCT domains that in BRCA1 are common targets for germline mutations segregating with breast and ovarian cancer susceptibility. BARD1 has been suggested to play a role, both independently and in conjunction with BRCA1, in several functions associated with DNA repair and tumour suppression.

- To investigate whether aberrations in the BARDI gene predispose to hereditary breast and/or ovarian cancer, the index cases of 126 Finnish cancer families were analysed. Altogether four missense and three synonymous alterations affecting protein encoding regions were observed, six of which were classified as neutral polymorphisms.

- The Cys557Ser alteration, locating to a defined region of BARD1 needed for induction of apoptosis and possibly also transcriptional regulation (through BLC3 and NFKB), was seen at elevated frequency in the studied cancer family material compared to healthy controls $(5.6 \vee 1.4 \%, p=0.005)$. The highest prevalence of Cys557Ser was found among the subgroup of 94 breast cancer patients, whose family history did not include ovarian cancer $(7.4 \vee 1.4 \%, p=0.001)$. The current study provides evidence that BARD 1 Cys557Ser may be a commonly occurring and mainly breast cancer predisposing allele.

BRCAl independent functions of BARDl. In addition, the effects of reduced Bardl expression have been studied in murine mammary epithelial cell cultures, where it was associated with complex cellular changes suggestive of a premalignant phenotype. ${ }^{29}$ Moreover, a recent study in mice showed that loss of Bard 1 results in early embryonic lethality and chromosomal instability, indicating a role of Bardl in maintenance of genomic integrity. The phenotype of Bardl null mice was found to be remarkably similar to that of Brcal nulls, further emphasising the functional relationship between these two proteins. ${ }^{30}$

Based on these facts, BARDI seems a plausible target for cancer inducing germline mutations. To explore this possibility, index cases of 126 Finnish breast and/or ovarian cancer

Abbreviations: aa, amino acid; $\mathrm{BRCT}, \mathrm{BRCAl}$ carboxy-terminal; $\mathrm{Cl}$, confidence interval; CSGE, conformation sensitive gel electrophoresis; CSTF1, cleavage stimulation factor subunit 1 ; OR, odds ratio 
families were analysed for mutations located in the protein encoding regions and intron-exon boundaries. Our results suggest a possible role for BARDI in hereditary susceptibility to breast cancer.

\section{METHODS}

The index cases of 126 breast and/or ovarian cancer families originating from northern Finland were selected for the screening of BARDl germline mutations. Of the studied families, 94 were associated with breast, 29 with breastovarian and three with ovarian cancer. All index cases had been diagnosed with either breast or ovarian cancer. Inclusion criteria for the 75 high risk families were the following: (1) three or more cases of breast and/or ovarian cancer in first or second degree relatives, or (2) two cases of breast and/or ovarian cancer in first or second degree relatives, of which at least one had early disease onset ( $\leqslant 35$ years), bilateral disease, or multiple primary tumours. Most of the high risk families displayed three or more cancer cases. The remaining 51 families with moderate disease susceptibility displayed two cases of breast and/or ovarian cancer in first or second degree relatives. All of the high risk families had previously been screened for germline mutations in BRCA1, BRCA2, CHK2, and TP53, ${ }^{31-33}$ and ten families showed alterations in BRCAl or BRCA2. The occurrence of the $B A R D 1$ Cys557Ser alteration was also tested in 188 breast cancer patients without known family history of the disease, and DNA samples from 1018 anonymous cancer free blood donors served as controls. Both reference groups originated from the same geographical region as the studied cancer families. All patients had given their informed consent for obtaining pedigree data and blood specimens for a study on cancer susceptibility gene mutations. Approval to perform the study was obtained from the Ethical Board of the Northern Ostrobotnia Health Care District and the Finnish Ministry of Social Affairs and Health.

DNA was extracted from blood lymphocytes using either the standard phenol-chloroform protocol or the Puregene D$50 \mathrm{~K}$ purification kit (Gentra, Minneapolis, MN, USA). The screening of protein encoding and exon-intron boundary regions of BARDI was done by conformation sensitive gel electrophoresis (CSGE), ${ }^{34}$ and samples with a band shift were reamplified and purified with the QIAquick PCR Purification Kit (Qiagen, Hilden, Germany). Sequencing analysis was performed using the Li-Cor IR ${ }^{2} 4200-\mathrm{S}$ DNA Analysis system (Li-Cor, Lincoln, NS, USA) and the SequiTherm EXCEL II DNA Sequencing Kit-LC (Epicentre Technologies, Madison, WI, USA). Oligonucleotides for CSGE and sequencing were designed by using Primer3 software, utilising sequence information obtained from public databases. Oligonucleotide sequences and PCR conditions for CSGE and sequencing are available upon request.

The observed differences in mutation frequencies between the hereditary or sporadic group of breast cancer patients and control samples were analysed by Fisher's exact test. MannWhitney's U test was used to compare mean ages of disease onset between alteration carriers and non-carriers. All p values were two sided. Statistical analyses were carried out with SPSS version 12.0 for Windows (SPSS, Chicago, IL, USA).

\section{RESULTS AND DISCUSSION}

The screening of index cases of breast and/or ovarian cancer families for BARDI germline mutations revealed four missense and three synonymous changes within the protein encoding region (table 1). Of these, the previously observed Cys557Ser missense alteration occurred in multiple families and appeared to be associated with cancer predisposition. The other six coding region variants were considered neutral
Table 1 Observed sequence variation in the protein encoding regions of the BARDI gene

\begin{tabular}{|c|c|c|c|c|c|}
\hline \multirow[b]{2}{*}{ Exon } & \multirow[b]{2}{*}{ Nt change } & \multirow[b]{2}{*}{$\begin{array}{l}\text { Effect on } \\
\text { protein }\end{array}$} & \multicolumn{3}{|c|}{ Allele frequency* } \\
\hline & & & $\begin{array}{l}\text { Familial } \\
\text { cases }\end{array}$ & $\begin{array}{l}\text { Sporadic } \\
\text { cases }\end{array}$ & Controls \\
\hline \multirow[t]{3}{*}{4} & $682 \mathrm{~A} \rightarrow \mathrm{C}$ & Gly203Gly & $\begin{array}{l}0.8 \% \\
(1 / 126)\end{array}$ & ND & $-(0 / 350)$ \\
\hline & $1126 \mathrm{G} \rightarrow \mathrm{C}$ & Thr351Thr† & $\begin{array}{l}21 \% \\
(27 / 126)\end{array}$ & ND & ND \\
\hline & $1207 C \rightarrow G$ & Ser378Args & $\begin{array}{l}48 \% \\
(61 / 126)\end{array}$ & ND & ND \\
\hline \multirow[t]{3}{*}{6} & $1591 \mathrm{C} \rightarrow \mathrm{T}$ & His506His§థ & $\begin{array}{l}9.5 \% \\
(12 / 126)\end{array}$ & ND & $\begin{array}{l}16 \% \\
(24 / 150)\end{array}$ \\
\hline & $1592 \mathrm{G} \rightarrow \mathrm{A}$ & Val507Met†§థ & $\begin{array}{l}56 \% \\
(70 / 126)\end{array}$ & ND & $\begin{array}{l}47 \% \\
(70 / 150)\end{array}$ \\
\hline & $1743 G \rightarrow C$ & Cys557Ser†‡ & $\begin{array}{l}5.6 \% \\
(7 / 126)\end{array}$ & $\begin{array}{l}2.7 \% \\
(5 / 188)\end{array}$ & $\begin{array}{l}1.4 \% \\
(14 / 1018)\end{array}$ \\
\hline 10 & $2045 C \rightarrow T$ & Arg658Cyst & $\begin{array}{l}3.2 \% \\
(4 / 126)\end{array}$ & ND & $\begin{array}{l}3.0 \% \\
(9 / 300)\end{array}$ \\
\hline
\end{tabular}

polymorphisms, as most of them also displayed similar allele frequencies in controls, occurred in the SNP database, or have been reported in other studies, ${ }^{15}{ }^{17}$ and none of them appeared to have a significant effect on protein function. In addition, a large number of apparently harmless intronic changes were found (data not shown).

Cys557Ser was the only possible disease related alteration in BARDl observed in the present study. Of the index cases from the studied breast and/or ovarian cancer families, 5.6\% (7/126) were found heterozygous for the Cys557Ser allele. The same alteration was also seen in $1.4 \%$ of the cancer free controls $(\mathrm{n}=1018)$, but at significantly lower incidence ( $p=0.005 ;$ OR $4.2 ; 95 \%$ CI 1.7 to 10.7$)$. Interestingly, in the hereditary material all seven index cases with Cys557Ser belong to a subgroup of 94 families displaying breast but not ovarian cancer, giving a prevalence of $7.4 \%(p=0.001$; OR 5.8; $95 \%$ CI 2.3 to 14.7). All index patients exhibiting the Cys557Ser allele were negative for BRCA1 and BRCA2 germline mutations. Cys557Ser was also observed in five of 188 $(2.7 \%)$ breast cancer cases without known family history of the disease, the frequency being slightly, but not significantly, higher than among control subjects $(\mathrm{p}=0.2$; $\mathrm{OR}=2.0 ; 95 \%$ CI 0.7 to 5.5). Altogether, the obtained results indicate that Cys557Ser may be a low penetrance breast cancer susceptibility allele. Interestingly, BARDI maps to $2 \mathrm{q} 34-\mathrm{q} 35$, which is relative close to the $2 \mathrm{q} 32$ chromosome region indicated by a genome-wide linkage analysis to segregate with breast cancer predisposition in some Finnish breast cancer families. ${ }^{35}$

To further evaluate the association between Cys557Ser and cancer susceptibility, the mutation status of other available affected or unaffected family members was analysed. In the pedigree shown in fig 1 , the Cys557Ser allele was seen in a woman with breast cancer at age 75 , and in her two daughters diagnosed with breast cancer at ages 49 and 53 . The third daughter did not show the missense alteration and was cancer free at age 63. In addition, the sister of the proband developed uterine cancer at the age of 40 , but no DNA was available for the testing of mutation status. Unfortunately, in the remaining six families displaying the Cys557Ser alteration, only a small number of additional DNA samples were available for analysis: one individual with breast cancer at age 80 , another with bilateral breast cancer at ages 40 and 53, and two individuals with uterine cancer did not carry the alteration. Thus, despite of a history of breast, and in some members of the families, other cancers as 


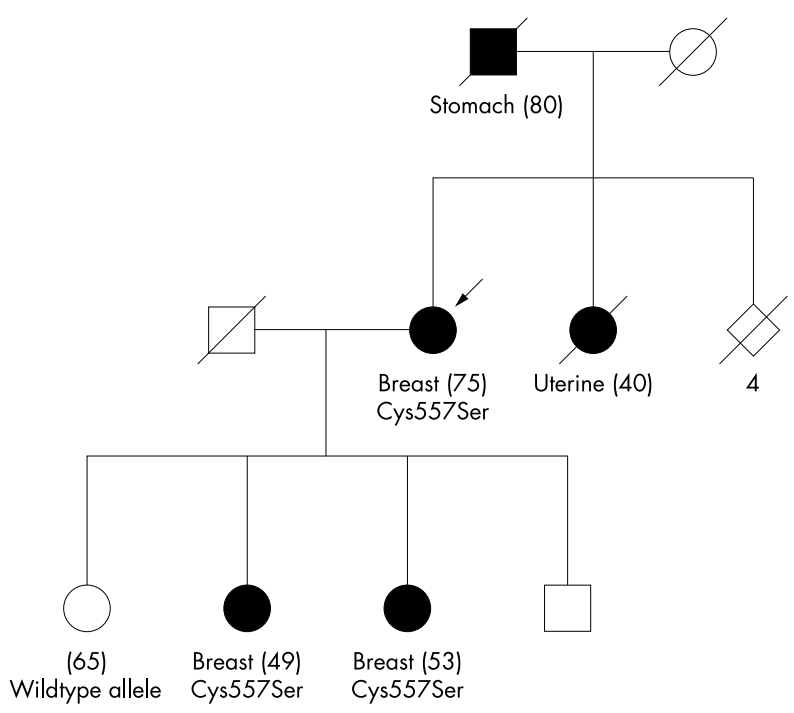

Figure 1 Pedigree of a Finnish cancer family showing the occurrence of the BARD1 Cys557Ser allele. Filled symbols indicate individuals with cancer, and the age at diagnosis is marked after the malignancy. For the disease free individual homozygous for the wildtype allele, the age at monitoring is shown. The arrow shows the index case.

well, the segregation of Cys557Ser with the disease could not be conclusively determined. In the studied families, the mean age at breast cancer diagnosis in Cys557Ser carriers was 56.8 years (ranging from 42 to 75 years), and thus somewhat higher compared to 51.9 years in index cases without BARD1 alteration, and 48.2 years in patients belonging to $B R C A l$ and $B R C A 2$ families. However, the difference between ages of onset was not statistically significant.

In addition to the current study, involvement of BARDI alterations in breast and ovarian cancer development has been suggested in three previous studies, two of which also reported the Cys557Ser variant. ${ }^{15-17}$ Cys557Ser was initially seen in sporadic Caucasian breast/ovarian/uterine tumour material with a frequency of $2 \%$, and was classified as a rare polymorphism. ${ }^{15}$ Later, in an Italian study of 40 breast and/or ovarian cancer families, the alteration was observed in four women belonging to the same family. ${ }^{16}$ Three of the women had breast or breast/ovarian cancer and the fourth was unaffected by the age of 39. As Cys557Ser was not present among any of the studied 60 controls or 20 sporadic cases, it was suggested to be a possible cancer susceptibility allele. The prevalence of $5.6 \%$ for BARDI Cys557Ser in the Finnish cancer family material is somewhat higher than the $2.5 \%$ reported in the Italian study, ${ }^{16}$ and as the alteration was not observed in Japanese families, ${ }^{17}$ it may indicate that it is of European/Caucasian origin. In contrast to previous studies, we observed that the occurrence of the Cys557Ser allele in the hereditary material was restricted to patients whose family history did not include ovarian cancer. However, due to the small number of ovarian and breast/ovarian cancer families analysed in the current study, a possible association of Cys557Ser with ovarian cancer cannot be excluded. Besides Cys557Ser, the following BARDI alterations, Asn295Ser, Lys312Asn, Asn470Ser, Gln564His, and 1144del21bp, have also been proposed to be related to cancer predisposition, ${ }^{15-17}$ but none of these changes were seen in our study.

Critical mutations in either BRCAl or BARDI have been shown to inhibit many of the essential functions of the BARDl protein. For instance, the cancer associated BARDl Gln564His change, which affects a residue that is located only eight amino acids from Cys557Ser (fig 2), results in reduced binding of CSTF1. This was found to abolish the inhibition of polyadenylation in response to DNA damage, indicating a link between mRNA processing and tumour suppression..$^{23}$ The Gln564His allele is also defective in apoptotic activity, suggesting a role of BARDl in cancer prevention by mediating the signalling between genotoxic stress and induction of TP53 dependent apoptosis. ${ }^{27}$ Recently,

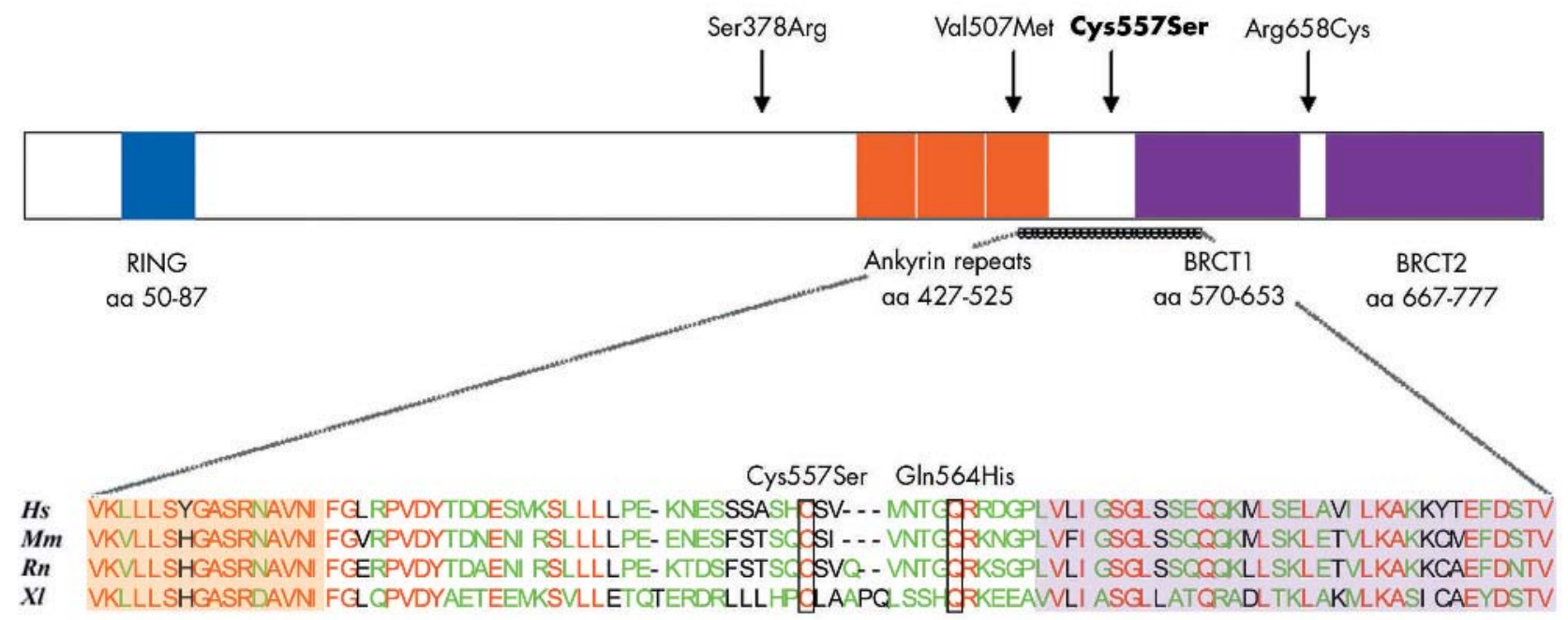

Figure 2 Schematic structure of the human BARD1 protein with highlighted window showing the amino acid (aa) sequence for residues 510-604, a region crucial for induction of apoptosis, ${ }^{36}$ and a comparison of homology between $H$. sapiens $(H s), M$. musculus $(M m), R$. norvegicus $(R n)$, and $X$. laevis (X). The RING domain (blue), three ankyrin repeats (orange) and two BRCT regions (purple), and their aa positions are displayed. The location of the possible breast cancer related Cys557Ser and other non-synonymous exon region variants seen in the present study are shown above the diagram. In the sequence alignment, residues identical in all four species are coloured red and biochemically similar residues are in green. The positions of Cys557Ser and the previously observed breast/ovarian/uterine cancer associated Gln564His variant are boxed. 
it was discovered that the minimal region in mouse Bard 1 required for apoptosis induction maps between the ankyrin repeats and the BRCT domains, encompassing amino acids 510 through $604 .^{36}$ Furthermore, a BARDl fragment composed of half of the ankyrin region through the BRCT domains (residues 464-777) binds in vitro to the ankyrin repeats of $\mathrm{BCL} 3{ }^{28}$ The minimal segments crucial for the binding to BCL3 or CSTF1 have not yet been determined. In this context, it would be important to examine whether Cys557Ser also has an effect on protein function. Cysteine residues are often crucial for the formation of disulfide bridges within and between proteins, and the substitution can therefore have profound effects on protein stability and folding. Cysteine 557 is conserved between several species (Homo sapiens, Mus musculus, Rattus norvegicus, Xenopus laevis; fig 2), as is also the case for Gln564, even if neither of them falls within the putative functional domains of the protein. Recently, BRCAl/BARDl orthologs were also discovered in Caenorhabditis elegans, ${ }^{37}$ but neither Cys557 nor Gln564 was found conserved in the worm Ce-BRD-1 protein. Currently, corresponding sequence data from other more diverged species, such as yeast or flies, are not available.

The two main susceptibility genes BRCAl and BRCA2 explain only part of the hereditary predisposition to breast and/or ovarian cancer, the mutation incidence being particularly low in families with four or less cases of breast cancer and typically without ovarian cancer. As it currently appears unlikely that mutations in any single novel susceptibility gene could account for a significant fraction of the remaining families, a polygenic model has been proposed..$^{38}{ }^{39}$ This model suggests that in the absence of BRCA1 and BRCA2 alterations, a majority of the cancer cases clustering within a family could be due to the multiplicative effect of various low to moderate penetrance genes, perhaps in combination with environmental factors. Thus, the finding that BARDI Cys557Ser associates with breast cancer predisposition in families negative for mutations in BRCAl and BRCA2, suggests that the effect on its own may be sufficient. On the other hand, it is possible that the Cys557Ser alteration may cosegregate with other currently unknown disease related alleles, and that the variation in age at disease onset could be a consequence of this phenomenon. The slight, but not statistically significant increase in the frequency of the Cys557Ser allele also among breast cancer patients without a known family history of the disease $(2.7 \%)$ may be a reflection of its incomplete phenotypic expression. Interestingly, a large previous investigation has shown that the cancer associated $C H K 2$ 1100delC allele also displays similar frequencies in BRCA1 and BRCA2 mutation negative breast cancer families, unselected breast cancer cases, and healthy controls, ${ }^{40}$ as was seen in the current study for BARDI Cys557Ser. The effect of these two alterations on cancer risk may also be comparable. Altogether, these findings indicate there are common sequence variants which slightly, but notably, enhance the risk of cancer. ${ }^{40}$

Based on published data, the role of BARDI in predisposition to breast cancer remains equivocal and unquestionably warrants further studies. According to the results obtained in the current study, individuals heterozygous for the Cys557Ser allele appear to be at increased risk of breast cancer. The observed incidence of $7.4 \%$ in the studied breast cancer families compared to $1.4 \%$ in healthy controls suggests that it may be a relatively common susceptibility allele associated with incomplete disease penetrance. However, in the absence of direct functional assays, the significance of Cys557Ser on breast cancer development cannot be properly assessed. Therefore, despite interesting results, more extensive studies will still be needed to address the role of BARDI in breast cancer predisposition.

\section{ACKNOWLEDGEMENTS}

The authors wish to thank Drs Tuija Löppönen, Outi Vierimaa, Jaakko Ignatius, Guillermo Blanco, and Ulla Puistola, and nurse Outi Kajula for their help with patient contacts. We are grateful to Dr Pentti Nieminen for his support and advice with the statistical analyses. The participation of all patients is greatly appreciated.

\section{ELECTRONIC-DATABASE INFORMATION}

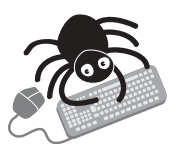

Accession numbers and URLs are as follows: GenBank: AH005849; U76638; Primer3 software, http://frodo.wi.mit.edu/cgi-bin/primer3/ primer3_www.cgi; SNP database, http:// www.ncbi.nlm.nih.gov/SNP/; NCBI Locus Link, http://www.ncbi.nlm.nih.gov/LocusLink/

\section{Authors' affiliations}

S-M Karppinen, K Heikkinen, K Rapakko, R Winqvist, Department of Clinical Genetics, Oulu University Hospital/University of Oulu, PO Box 24, FIN-90029 OYS, Finland

This study was supported by the Academy of Finland, Cancer Foundation of Northern Finland, Finnish Cultural Foundation, University of Oulu, Oulu University Hospital and Finnish Breast Cancer Group.

Conflict of interest: none declared.

Correspondence to: R Winqvist, Department of Clinical Genetics, Oulu University Hospital/University of Oulu, PO Box 24, FIN-90029 OYS, Finland; robert.winqvisł@oulu.fi

Revised version received 10 May 2004

Accepted for publication 10 May 2004

\section{REFERENCES}

1 Claus EB, Risch N, Thompson WD. Genetic analysis of breast cancer in the cancer and steroid hormone study. Am J Hum Genet 1991;48: 232-42.

2 Miki Y, Swensen J, Shattuck-Eidens P, Futreal PA, Harshman K, Tavtigian S, Liu Q, Cochran C, Bennett LM, Ding W, Bell R, Rosenthal J, Hussey C, Tran T, McClure M, Frye C, Hattier T, Phelps R, Haugen-Strano A, Katcher H, Yakumo K, Gholami Z, Shaffer D, Stone S, Bayer S, Wray C, Bogden R, Dayananth P, Ward J, Tonin P, Narod S, Bristow PK, Norris FH, Helvering L, Morrison P, Rosteck P, Lai M, Barret JC, Lewis C, Neuhausen S, CannonAlbright L, Goldgar D, Wiseman R, Kamb A, Skolnick MH. A strong candidate for the breast and ovarian cancer susceptibility gene BRCA1. Science 1994; 266:66-71.

3 Wooster R, Bignell G, Lancaster J, Swift S, Seal S, Mangion J, Collins N, Gregory S, Gumbs C, Micklem G, Barfoot R, Hamoudi R, Patel S, Rice C, Biggs P, Hashim Y, Smith A, Connor F, Arason A, Gudmundsson J, Ficenec D, Kelsell D, Ford D, Tonin P, Bishop DT, Spurr NK, Ponder BAJ, Eeles R, Peto J, Devilee P, Cornelisse C, Lynch H, Narod S, Lenoir G, Egilsson V, Barkadottir RB, Easton DF, Bentley DR, Futreal PA, Ashworth A, Stratton MR. Identification of the breast cancer susceptibility gene BRCA2. Nature 1995;378:789-92.

4 Ford D, Easton DF, Peto J. Estimates of the gene frequency of BRCAl and its contribution to breast and ovarian cancer incidence. Am J Hum Genet 1995; 57: 1457-62.

5 Ford D, Easton DF, Stratton M, Narod S, Goldgar D, Devilee P, Bishop DT, Weber B, Lenoir G, Chang-Claude J, Sobol H, Teare MD, Struewing J, Arason A, Scherneck S, Peto J, Rebbeck TR, Tonin P, Neuhausen S, Barkardottir R, Eyfjord J, Lynch H, Ponder BA, Gayther SA, ZeladaHedman $M$, and the Breast Cancer Linkage Consortium. Genetic heterogeneity and penetrance analysis of the BRCA1 and BRCA2 genes in breast cancer families. Am J Hum Genet 1998;62:676-89.

6 Rahman N, Stratton MR. The genetics of breast cancer susceptibility. Annu Rev Genet 1998;32:95-121.

7 Wooster R, Weber BL. Breast and ovarian cancer. N Engl J Med 2003;348:2339-47

8 Deng CX, Brodie SG. Roles of BRCA1 and its interacting proteins. Bioessays 2000;22:728-37.

9 Venkitaraman AR. Cancer susceptibility and the functions of BRCA1 and BRCA2. Cell 2002; 108:171-82.

10 Rosen EM, Fan S, Pestell RG, Goldberg ID. BRCA1 gene in breast cancer. J Cell Physiol 2003;196:19-41.

11 Wu LC, Wang ZW, Tsan JT, Spillman MA, Phung A, Xu XL, Yang MCW Hwang LY, Bowcock AM, Baer R. Identification of a RING protein that can interact in vivo with the BRCA1 gene product. Nat Genet 1996; 14:430-40. 
12 Meza JE, Brzovic PS, King MC, Klevit RE. Mapping the functional domains of BRCA 1. Interaction of the ring finger domains of BRCA1 and BARD1. J Biol Chem 1999;274:5659-65.

13 Morris JR, Keep NH, Solomon E. Identification of residues required for the interaction of BARD1 with BRCA1. J Biol Chem 2002;277:9382-6.

14 Brzovic PS, Meza JE, King MC, Klevit RE. BRCA1 RING domain cancerpredisposing mutations. Structural consequences and effects on proteinprotein interactions. J Biol Chem 2001;276:41399-406.

15 Thai TH, Du F, Tsan JT, Jin Y, Phung A, Spillman MA, Massa HF, Muller CY, Ashfaq R, Mathis JM, Miller DS, Trask BJ, Baer R, Bowcock AM. Mutations in the BRCA1-associated RING domain (BARD1) gene in primary breast, ovarian and uterine cancers. Hum Mol Genet 1998;7:195-202.

16 Ghimenti C, Sensi E, Presciuttini S, Brunetti IM, Conte P, Bevilacqua G, Caligo MA. Germline mutations of the BRCAl-associated ring domain (BARD1) gene in breast and breast/ovarian families negative for BRCA1 and BRCA2 alterations. Genes Chromosomes Cancer 2002;33:235-42.

17 Ishitobi M, Miyoshi Y, Hasegawa S, Egawa C, Tamaki Y, Monden M, Noguchi S. Mutational analysis of BARD1 in familial breast cancer patients in Japan. Cancer Lett 2003;200:1-7.

18 Sedgwick SG, Smerdon SJ. The ankyrin repeat: a diversity of interactions on a common structural framework. Trends Biochem Sci 1999;24:311-6.

19 Jin Y, Xu XL, Yang MC, Wei F, Ayi TC, Bowcock AM, Baer R. Cell cycledependent colocalization of BARD1 and BRCA1 proteins in discrete nuclear domains. Proc Natl Acad Sci U S A 1997:94:12075-80.

20 Scully R, Chen J, Ochs RL, Keegan K, Hoekstra M, Feunteun J, Livingston DM Dynamic changes of BRCA1 subnuclear location and phosphorylation state are initiated by DNA damage. Cell 1997;90:425-35.

21 Westermark UK, Reyngold M, Olshen AB, Baer R, Jasin M, Moynahan ME. BARDI participates with BRCA1 in homology-directed repair of chromosome breaks. Mol Cell Biol 2003;23:7926-36.

22 Kleiman FE, Manley JL. Functional interaction of BRCA1-associated BARD1 with polyadenylation factor CstF-50. Science 1999;285:1576-9.

23 Kleiman FE, Manley JL. The BARD1-CstF-50 interaction links mRNA 3 ' end formation to DNA damage and tumor suppression. Cell 2001;104:743-53.

24 Hashizume R, Fukuda M, Maeda I, Nishikawa H, Oyake D, Yabuki Y, Ogata H, Ohta T. The RING heterodimer BRCA I-BARDI is a ubiquitin ligase inactivated by a breast cancer-derived mutation. J Biol Chem 2001;276:14537-40.

25 Parvin JD. BRCA1 at a branch point. Proc Natl Acad Sci U S A $2001 ; 98: 5952-4$

26 Fabbro $M$, Rodriguez JA, Baer R, Henderson BR. BARDI induces BRCAI intranuclear foci formation by increasing RING-dependent BRCA1 nuclear import and inhibiting BRCAl nuclear export. J Biol Chem 2002;277:21315-24.

27 Irminger-Finger I, Leung WC, Li J, Dubois-Dauphin M, Harb J, Feki A, Jefford CE, Soriano JV, Jaconi M, Montesano R, Krause KH. Identification of BARDI as mediator between proapoptotic stress and p53-dependent apoptosis. Mol Cell 2001;8:1255-66.

28 Dechend R, Hirano F, Lehmann K, Heissmeyer V, Ansieau S, Wulczyn FG, Scheidereit $\mathrm{C}$, Leutz A. The Bcl-3 oncoprotein acts as a bridging factor between NF-kappaB/Rel and nuclear co-regulators. Oncogene 1999; 18:3316-23.
29 Irminger-Finger I, Soriano JV, Vaudan G, Montesano R, Sappino AP. In vitro repression of Brcal-associated RING domain gene, Bardl, induces phenotypic changes in mammary epithelial cells. J Cell Biol 1998; 143:1329-39.

30 McCarthy EE, Celebi JT, Baer R, Ludwig T. Loss of Bard1, the heterodimeric partner of the Brcal tumor suppressor, results in early embryonic lethality and chromosomal instability. Mol Cell Biol 2003;23:5056-63.

31 Huusko P, Pääkkönen K, Launonen V, Pöyhönen M, Blanco G, Kauppila A Puistola $U$, Kiviniemi $H$, Kujala $M$, Leisti J, Wingvist R. Evidence of founder mutations in Finnish BRCA1 and BRCA2 families. Am J Hum Genet 1998;62:1544-8

32 Allinen M, Huusko P, Mäntyniemi S, Launonen V, Winqvist R. Mutation analysis of the CHK2 gene in families with hereditary breast cancer. Br J Cancer 2001;85:209-212.

33 Rapakko K, Allinen M, Syriäkoski K, Vahteristo P, Huusko P, Vahakangas K, Eerola H, Kainu T, Kallioniemi OP, Nevanlinna H, Winqvist R. Germline TP53 alterations in Finnish breast cancer families are rare and occur at conserved mutation-prone sites. Br J Cancer 2001;84:116-9.

34 Körkkö J, Annunen S, Pihlajamaa T, Prockop DJ, Ala-Kokko L. Conformation sensitive gel electrophoresis for simple and accurate detection of mutations: comparison with denaturing gradient gel electrophoresis and nucleotide sequencing. Proc Natl Acad Sci U S A 1998:95:1681-5.

35 Huusko P, Juo SH, Gillanders E, Sarantaus L, Kainu T, Vahteristo P, Allinen $M$, Jones M, Rapakko K, Eerola H, Markey C, Vehmanen P, Gildea D, Freas-Lutz D, Blomqvist C, Leisti J, Blanco G, Puistola U, Trent J, Bailey-Wilson J, Winqvist R, Nevanlinna H, Kallioniemi OP. Genome-wide scanning for linkage in Finnish breast cancer families. Eur $J$ Hum Genet 2004; 12:98-104

36 Jefford CE, Feki A, Harb J, Krause KH, Irminger-Finger I. Nuclear-cyłoplasmic translocation of BARDI is linked to its apoptotic activity. Oncogene 2004;23:3509-20.

37 Boulton SJ, Martin JS, Polanowska J, Hill DE, Gartner A, Vidal M. BRCA1/ BARD1 orthologs required for DNA repair in Caenorhabditis elegans. Curr Biol 2004; 14(1):33-9.

38 Antoniou AC, Pharoah PD, McMullan G, Day NE, Stratton MR, Peto J, Ponder BJ, Easton DF. A comprehensive model for familial breast cancer incorporating BRCA1, BRCA2 and other genes. $\mathrm{Br} J$ Cancer 2002;86:76-83.

39 Pharoah PD, Antoniou A, Bobrow M, Zimmern RL, Easton DF, Ponder BA. Polygenic susceptibility to breast cancer and implications for prevention. Nat Genet 2002;31:33-6.

40 Meijers-Heiiboer $\mathbf{H}$, van den Ouweland A, Kliin J, Wasielewski M, de Snoo A, Oldenburg R, Hollestelle A, Houben M, Crepin E, van Veghel-Plandsoen M, Elstrodt F, van Duijn C, Bartels C, Meijers C, Schutte M, McGuffog L, Thompson D, Easton D, Sodha N, Seal S, Barfoot R, Mangion J, Chang Claude J, Eccles D, Eeles R, Evans DG, Houlston R, Murday V, Narod S, Peretz T, Peto J, Phelan C, Zhang HX, Szabo C, Devilee P, Goldgar D, Futreal PA, Nathanson KL, Weber B, Rahman N, Stratton MR. CHEK2-Breast Cancer Consortium. Low-penetrance susceptibility to breast cancer due to CHEK2(*)1 100delC in noncarriers of BRCA1 or BRCA2 mutations. Nat Genet 2002;31:55-9. 